\title{
IgE and IgE-rheumatoid factors in circulating immune complexes in rheumatoid arthritis
}

\author{
K. MERETEY,${ }^{1}$ A. FALUS,${ }^{1}$ C. C. ERHARDT ${ }^{2}$ AND R. N. MAINI ${ }^{2}$ \\ From the ${ }^{1}$ National Institute of Rheumatology and Physiotherapy, Budapest, Hungary, and the ${ }^{2}$ Division of \\ Clinical Immunology, Kennedy Institute of Rheumatology, 6 Bute Gardens, Hammersmith, London W6 7DW
}

SUMMARY The sera of 21 patients with rheumatoid arthritis (RA), 11 patients with systemic lupus erythematosus (SLE), and 20 healthy subjects were analysed for the presence of IgE in immune complex fractions. These fractions were isolated by polyethylene glycol precipitation and gel filtration. Thirteen sera from RA patients contained IgE immune complexes (IC) and 11 of these were from patients with extra-articular manifestations. One SLE and none of the control sera contained such material. The serum IgE level did not correlate with IgE content of the IC fractions. Higher mean serum IgE levels were found in RA patients with extra-articular complications than in controls or RA patients with joint disease only, but the differences did not reach statistical significance. IgE anti-rabbit IgG (IgE rheumatoid factors) could be demonstrated in some IgE positive IC fractions. Antibodies to IgE, in 2 instances characterised as belonging to IgG class, were also found in ICs. This suggests the presence of anti IgE complexes. It is suggested that IgE, including some with rheumatoid factor activity, is contained in complexes which may be involved in some extra-articular manifestations of RA.

Immune complexes (ICs) that occur in rheumatoid arthritis (RA) are heterogeneous in respect of both size and composition. The ICs in RA consist mostly of IgG, IgM, and complement factors. ${ }^{1-3}$ Rheumatoid factors are also regularly described in these ICs and may be involved in the evolution of systemic manifestations. ${ }^{45}$

In a recent study antinuclear antibodies of IgE type were found to occur in a complexed form in the sera of RA patients. ${ }^{6}$ IgE-type complexes have also been described in the sera of atopic patients. ${ }^{78}$

A double polyethylene glycol (PEG) precipitation test was developed to detect IgE in the immunecomplex-rich fraction isolated from sera. By this technique IgE-containing complexes were found in some RA patients. ${ }^{9}$

The present studies were undertaken in order to characterise these IgE-type ICs in rheumatoid arthritis and to correlate them with clinical manifestations.

\section{Materials and methods}

Patients. Twenty-one RA and 11 SLE patients, as well as 20 healthy persons, were included in this study. All

Accepted for publication 21 May 1981.

Correspondence to Dr R. N. Maini. patients with RA had classical or definite $\mathrm{RA},{ }^{10}$ and patients with SLE had 4 or more ARA criteria. ${ }^{11}$ Fourteen RA patients had extra-articular manifestations (nodules, pulmonary disease, vasculitis and neuropathy) and were evaluated as a separate group.

Sera were obtained in the active phase of the disease (elevated erythrocyte sedimentation rate and clinical assessment), and aliquots were stored at $-70^{\circ} \mathrm{C}$ until used.

Isolation of immune complexes. Immunecomplex-rich fractions were prepared as described previously. ${ }^{5}$ Briefly, sera were diluted with $3 \%$ PEG (PEG 6000, Fluka, Germany) to a final concentration of 1:50. After mixing and overnight incubation at $4^{\circ} \mathrm{C}$ the precipitates were washed with $3 \%$ PEG and redissolved in the original volume of the serum sample. Protein content was measured by the Lowry method, ${ }^{12}$ IgG, IgM, and IgA levels in ICs by radial immunodiffusion, ${ }^{13}$ and the $\mathrm{C} 3$ and $\mathrm{C} 4$ concentrations by means of rocket electrophoresis. ${ }^{14}$

Detection of IgE in ICs. We could detect IgE-type complexes by the double PEG precipitation test described previously. ${ }^{9}$ The redissolved PEG precipitates $(50 \mu \mathrm{l})$ were incubated with $50 \mu \mathrm{l}$ of ${ }^{125} \mathrm{I}$-antiIgE (Phaedebas RAST Isotope Unit, Pharmacia, Sweden). The labelled anti-IgE bound to the ICs 405 
were reprecipitated by $3 \%$ PEG (final concentration) and the pellet counted for radioactivity (Autogamma counter, Gamma Works, Hungary). Pellets with more than $3 \%$ of the added radioactivity were taken as a positive result ( $2 \mathrm{SD}$ above the mean of the nonspecific binding in 10 normal sera and $100 \mu \mathrm{g}$ aggregated IgG). IgE level in selected IC fractions and sera were measured by the Phadebas PRIST test (Pharmacia, Sweden). Gel filtration of the sera was performed on a Sephadex G-200 column in $0 \cdot 1 \mathrm{M}$ borate buffer at $\mathrm{Ph} 8 \cdot 1$. Peaks were collected concentrated by PEG 20000 (Serva) to the original volume and checked for IgE content by PRIST.

$I g E$ rheumatoid factors (RFs) in ICs. Rabbit IgGSephadex gel was used as solid phase immunosorbent to separate RFs (a gift from F. Peterfy, HUMAN Institute for Sera and Vaccine Production, Budapest). Sera, or isolated PEG fractions, were incubated with an aliquot of the immunosorbent, and after thorough washings the amount of IgE-RF activity was determined by the subsequent binding of ${ }^{125} \mathrm{I}$ anti-IgE.

Antibodies to IgE in PEG precipitates. Test for anti-IgE was performed on heat-treated serum or PEG precipitates. It was confirmed in separate experiments that heat treatment of sera at $56^{\circ} \mathrm{C}$ for 4 hours destroyed most of the immunoreactivity of IgE molecules. Such heat treated sera were incubated with a standard amount of IgE (10 IU $/ \mathrm{ml}$ Phadebas standard), and after overnight incubation the decrease in the available IgE was determined by PRIST. IgE was simultaneously measured in the heat-treated samples. Significant decrease of the

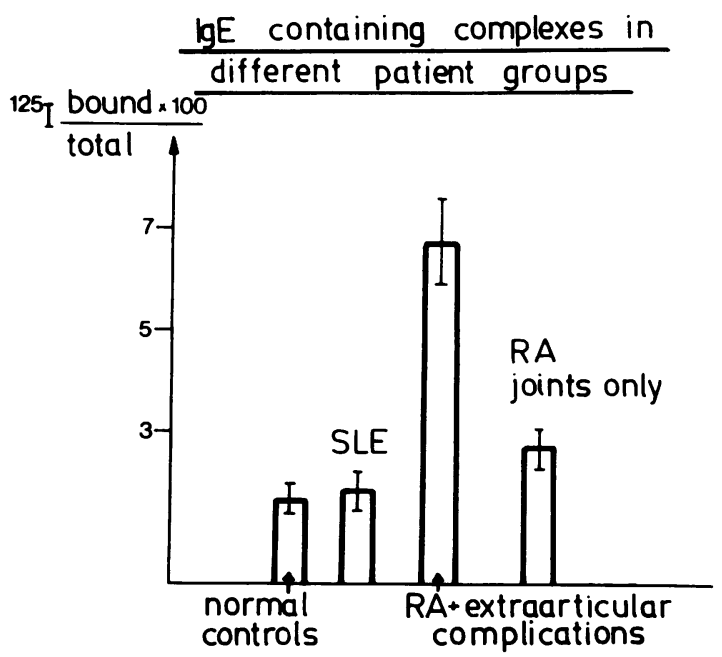

Fig. 1 Occurrence of IgE-containing PEG precipitates (immune complexes). Ordinate shows the percentage binding of ${ }^{125}$ I-anti-IgE. Mean \pm SEM.
Table 1 IgE level of sera

\begin{tabular}{lrc}
\hline Groups & $n$ & $I g E K U / l^{*}$ \\
\hline Normal controls & 20 & $59(45-82)$ \\
RA + extra-articular manifestation & 14 & $100(79-192)$ \\
RA 'joints only' & 7 & $22(13-37)$ \\
SLE & 11 & $78(49-123)$ \\
\hline
\end{tabular}

* Geometric mean calculated after e-log conversion of data and range of values within $1 \mathrm{SE}$.

measurable IgE content after incubation with heated serum, or with IC fractions, was taken as an evidence for the presence of anti-IgE activity.

IgG was isolated from ICs by diethyl aminoethyl (DEAE) cellulose ion exchange chromatography and its anti-IgE activity measured as described above.

Statistical analysis was done by comparing the mean values by Student's $t$ test. Serum IgE values were evaluated after e-log conversion of the results in order to compensate for the nonhomogeneity of the data. ${ }^{15}$

\section{Results}

Occurrence of complexes containing IgE in serum samples of RA and SLE patients. The isolated PEG precipitates from normal sera failed to bind significant amounts of anti-IgE (Fig. 1). The mean binding of the controls was $1.64 \pm 0 \cdot 18 \%$, and none of the samples bound more than $3 \%$ of the added ${ }^{125} \mathrm{I}$ antiIgE. Low binding was found in SLE sera (1.99 \pm $0 \cdot 29)$. High values were observed in RA cases. In patients with extra-articular manifestations 11 out of 14 sera were positive. The extra-articular RA group differed significantly from all other groups (mean $6 \cdot 8$ $\pm 1 \cdot 12, \mathrm{p}<0 \cdot 01)$. Patients with RA who had only joint disease showed a moderate increase in the mean value $(2.49 \pm 0.47 \%$ binding activity), but only 2 sera of the 7 studied showed binding higher than $3 \%$. This group differed significantly both from normal persons and from extra-articular RA cases $(p<0 \cdot 05)$.

IgE-level of sera. We determined the serum IgE levels of the samples to compare them with the presence of IgE-complexes (Table 1). The geometric means of sera from normal persons and RA patients

Table 2 Clinical features of RA and SLE patients related to the presence of $\mathrm{IgE} I \mathrm{Cs}$

\begin{tabular}{llllll}
\hline & \multicolumn{2}{l}{$R A$} & & \multicolumn{2}{l}{$S L E$} \\
\cline { 2 - 5 } \cline { 5 - 6 } & $+^{*}$ & - & $+^{*}$ & - \\
\hline Nodules & 6 & 1 & 0 & 0 \\
Pulmonary involvement & 6 & 0 & 0 & 0 \\
Renal involvement & 0 & 0 & 1 & 8 \\
Other features & 4 & 2 & 0 & 2 \\
\hline
\end{tabular}

${ }^{*}$ PEG fractions bind more $(+)$ or less $(-)$ than $3 \%$ of the added ${ }^{123} \mathrm{I}$ anti-IgE 
Table 3 IgE rheumatoid factors in immune complexes

\begin{tabular}{llll}
\hline Fractions & $\begin{array}{l}\text { Number of } \\
\text { samples }\end{array}$ & $\begin{array}{l}\text { IgE IC-positive } \\
\text { samples }\end{array}$ & $\begin{array}{l}\text { IgE-type RF } \\
\text { in IC }{ }^{\dagger}\end{array}$ \\
\hline 1st G-200 peak* & 6 & 3 & 2 \\
PEG fractions & 14 & 7 & 3 \\
\hline
\end{tabular}

* Samples were considered positive when the IgE level in the 1 st peak exceeded $5 \%$ of the total IgE level. +IgE RF test was considered positive if more than $1 \cdot 1 \%$ of the added ${ }^{125} \mathrm{I}$-anti-IgE was bound to the immunosorbent.

with joint disease alone were the lowest. The range and the mean of IgE concentration in SLE cases and in RA with extra-articular manifestations were raised, and they showed that in some patients the $\operatorname{IgE}$ levels were much higher than in the other groups. However, the mean differences were not significant. The IgE levels did not correlate with the amount of IgE in ICs $(r=0 \cdot 31)$.

The relationship of IgE-ICs to clinical features in $R A$ and nephropathy in SLE. The extra-articular features of patients with RA are summarised in Table 2 . We could conclude that extra-articular features, especially pulmonary involvement and nodules, correlated well with the presence of IgE-containing immune complexes. In contrast, patients with SLE nephropathy did not have IgE ICs in their serum.

Composition of PEG fractions in RA cases. Immunochemical analysis of PEG IC fractions revealed that $\operatorname{IgG}$ and $\operatorname{IgM}$ were the major components in all RA sera. IgA and complement ( $\mathrm{C} 3$ and C4) were also present in some ICs. All of the components could be detected more frequently in the extra-articular RA group than in the 'joints only' group. The IgE content of PEG precipitates correlated with both the protein $(r=0.53)$ and $I g G$ content $(\mathrm{r}=0.62)$. This indicated either that IgG and IgE ICs occurred in the same patients or that Ig and IgE were present in a complexed form.

Detection of IgE RFs in immune complexes. IgE IC-positive and negative serum samples were selected and fractionated on a Sephadex G-200 column. In 3 of the 6 sera fractionated $\mathrm{IgE}$ was found in the excluded peak, indicating that it was in a complexed form (Table 3 ). The concentrated first peaks were tested for their binding to solid-phase rabbit

Table 4 Anti-IgE in IC form

\begin{tabular}{llll}
\hline Fractions & $\begin{array}{l}\text { Number of } \\
\text { samples }\end{array}$ & $\begin{array}{l}\text { IgE ICt-positive } \\
\text { samples }\end{array}$ & Anti-IgE in IC \\
\hline 1st peaks of gel & 6 & 3 & 1 \\
$\quad$ filtration & 6 & 6 & 5 \\
PEG fractions & 14 & 4 & 2 \\
\hline IgG isolated* from & 9 & & \\
\hline
\end{tabular}

For details see Table 3. *By DEAE cellulose A 52 chromatography. $\div$ Measured by PRIST.
$\mathrm{IgG}$, and for IgE-class anti-IgG activity, measured by sequential binding as described. Two of the $3 \mathrm{IgE}$ IC-positive peaks contained IgE-type rheumatoid factors.

PEG fractions were also similarly tested for IgE RF (rheumatoid factor) activity on the rabbit IgG immunosorbent. Of the 7 IgE-positive PEG fractions 3 contained IgE RF activity.

Antibodies to IgE in immune complexes. The first peak of Sephadex G-200 gel filtrations were heat treated to destroy their IgE, and their anti-IgE content was estimated. Anti-IgE was found in one of the 3 IgE IC-positive macromolecular peaks studied (Table 4). Among the 6 PEG fractions positive for IgE ICs 5 contained anti-IgE activity. We isolated IgG from 9 PEG IC-rich fractions by ion exchange chromatography, and 2 bound IgE.

\section{Discussion}

It has been shown that IgE-mediated reactions are important in the localisation of circulating immune complexes in the serum sickness model in rabbits. ${ }^{16}$ Such a role for IgE in man has not been fully investigated. Our results suggest that IgE-containing fractions of serum, presumed to be immune complexes, are found in some patients with rheumatoid arthritis, especially those with extra-articular complications. However, since IgE ICs represent only a minor fraction of the whole immune complex pool present in such sera, it is not yet possible to state whether they play a special role in the pathogenesis of tissue lesions. It is likely that IgE ICs will passively traverse abnormally permeable vessels, but we suggest that they may localise in specific sites in tissues rich in $\operatorname{IgE}$ receptors.

The respiratory and gastrointestinal tracts are privileged sites for IgE-production. Recent studies have shown that IgE-rich complexes are detectable in the blood of asthmatic patients and in patients with food allergy. ${ }^{77}$ The finding of IgE ICs in rheumatoid patients with pulmonary manifestations raises the possibility of a similar origin. Our patients were not atopic, and IgE ICs were also found in patients with nonpulmonary extra-articular manifestations. However, we cannot exclude the involvement of IgE antibodies to extrinsic antigens in the sera of our patients.

All conditions with IgE-type immune complexes are possibly associated with an increased synthesis of $\mathrm{IgE}$. Though high IgE levels occur in allergy and in some infections ${ }^{18}$ data on the serum IgE level in RA and in patients with RA on drugs are contradictory. ${ }^{1920} \mathrm{~A}$ recent study ${ }^{21}$ has shown that serum IgE level was significantly higher in seropositive than seronegative RA, and it was suggested that drug therapy may be a contributory factor. 
We found normal IgE levels in all groups, but a tendency for a higher value was observed in the extra-articular RA group. One can suggest that in patients with extra-articular symptoms an exaggerated polyclonal immunoglobulin response leads to the increased level of IgE. Indeed, it has been suggested that high IgE levels may occur in some forms of immunodeficiency as part of abnormal immunoregulation, ${ }^{18}$ but no such data are available in autoimmune patients.

In this study the occurrence of $\operatorname{IgE}$ rheumatoid factors in immune complex fractions is described. Although a novel finding, it is not in itself surprising, since other isotype have been already described. It will be important to establish whether these autoantibodies have a special clinical significance. Other IgE autoantibodies have been described, for example. IgE-type granulocyte-specific antinuclear autoantibodies were reported in sera of patients suffering from RA or Felty's syndrome. ${ }^{6}$ IgE-type anti RNA antibodies were also thought to be present in studies in which RNA could induce histamine release from basophils of RA patients. ${ }^{22}$

IgM-type anti-IgE antibodies were detected in sera of healthy persons and in various patients. ${ }^{23}$ Our preliminary observations suggest that IgG class of anti-IgE antibodies may also be present in sera of some RA patients. While IgM-type antibodies agglutinated well, they did not release histamine. ${ }^{23}$ IgG type anti-IgE autoantibodies, however, might interact with cytophilic IgE and release histamine.

The finding of IgE ICs in RA contrasts with their absence in the nephropathy of SLE. Little is known about the reasons for the patterns of localisation of immune complexes in different organs in various diseases. IgE ICs and rheumatoid factors may be an additional factor which should be considered in the evolution of the subgroups of multisystem disease seen in RA.

This work was supported by the Scientific Research Council, Ministry of Health, Hungary (6-07-0304-01-2) (M). The authors wish to thank Lendvary Maria for the excellent technical assistance and Miss Carole Irving for typing the manuscript. We also acknowledge the support that the Arthritis and Rheumatism Council give to the Kennedy Institute.

\section{References}

1 Kunkel H G, Muller-Eberhard H J, Fudenberg H H, Tomasi T S Gammaglobulin complexes in rheumatoid arthritis and certain other conditions. J Clin Invest 1961; 40: 117-29.

2 Zubler R H, Nydegger U, Perrin L $\mathrm{H}$, et al. Circulating and intra-articular immune complexes in patients with rheumatoid arthritis-correlation of ${ }^{125} \mathrm{I}$-Clq binding activity with clinical and biological features of disease. J Clin Invest 1976; 57: 1308-19.
3 Roitt I V. Immunochemical characteristics of immune complexes in rheumatoid arthritis. International Symposium on Immunopathology of Rheumatoid Arthritis. London. Nov. 22-23.

4 Erhardt C C, Mumford P, Maini R N. The association of cryoglobulinaemia with nodules, vasculitis and fibrosing alveolitis in rheumatoid arthritis and their relationship to serum Clq binding activity and rheumatoid factor. Clin Exp Immunol 1979; 38: 405-13.

5 Falus A, Meretey K, Böhm U, Bozsoky S. Complexed rheumatoid factor measurements in sera, synovial fluids and in immune complex fractions. Experientia 1979; 35: 413-4.

6 Permin H, Wiik A. The prevalence of IgE type antinuclear antibodies in rheumatoid arthritis and systemic lupus erythematosus. Acta Pathol Microbiol Scand (C) 1978; 86: $245-9$.

7 Brostoff J, Johns P, Stanworth D. Complexed IgE in atopy. Lancet 1977; ii: 741-2.

8 Brostoff J, Crini C. Production of IgE complexes by allergen challenge in atopic patients and the effect of sodium chromoglycate. Lancet 1979; ii: 1268.

9 Meretey K, Böhm U, Falus A, Bozsoky S. Radioimmune double PEG precipitation technique for detecting complexed IgE. J Immunol Methods 1979; 26: 223-8.

10 Ropes M W, Bennett G A, Cobb S A, Jacox R, Jessar R A. Revision of diagnostic criteria in rheumatoid arthritis. Bull Rheum Dis 1958; 9: 175-6.

11 Cohen A S, Reynolds W E, Franklin E C. Preliminary criteria for the classification of systemic lupus erythematosus. Bull Rheum Dis 1971; 21: 643-8.

12 Lowry O H, Rosenbrough N J, Farr A L, Randal R J. Protein measurement with the folin phenol reagent. J Biol Chem 1951; 193: $265-8$.

13 Mancini G, Carbonara A O, Heremans J F. Immunochemical quantitation of antigen by single radial immunodiffusion. Immunochemistry 1965; 2: 235-54.

14 Laurell C B. Quantitative estimation of proteins by electrophoresis in agarose gel containing antibodies. Anal Biochem 1966; 13: 45-52.

15 Kjellman N I M, Johansson S G O, Roth A. Serum IgE levels in healthy children quantified by a sandwich technique (PRIST). Clin Allergy 1976; 6: 51-9.

16 Cochrane C G, Koffler D. Immune complexes disease of experimental animal and man. Adv Immunol 1973; 16: 185-264.

17 Brostoff J, Carini C, Wraith D G. Immune complexes in adverse reactions to foods 2 . Immunologic evidence for IgE complexes following food challenge. Allergol Immunopathol (Madr) 1980; 8: 459 .

18 Buckley R H, Becker W G. Abnormalities in the regulation of human IgE synthesis. Immunol Rev 1978; 41: 288-314.

19 Hunder G G, Gleich G J. Immunoglobulin levels in rheumatoid arthritis. Arthritis Rheum 1971; 14: 389-91.

20 Grennan D M, Palmer D G. Serum IgE concentrations in rheumatoid arthritis: lack of correlation with gold toxicity. $\mathrm{Br}$ Med J 1979; ii: 1477-8.

21 Dobloug J H, Forre U, Kass E, Thorsby E. HLA antigens and rheumatoid arthritis. Association between HLA-DRW4 positivity and IgM rheumatoid factor production. Arthritis Rheum 1980; 23: 309-13.

22 Permin H, Stahl P, Kov S, Norm S, Juhl F. Basophil histamine release by RNA, DNA and aggregated $\operatorname{IgG}$ examined in rheumatoid arthritis and systemic lupus erythematosus. Allergy 1978; 33: 15-28.

23 Williams R C Jr, Griffith R C, Emmons J D, Field R S. Naturally occurring human antiglobulins with specificity for gamma $E$. J Clin Invest 1972; 51: 955-63. 